\title{
A “différance sexual” Escrita e diferenças sexuais no pensamento de Jacques Derrida ${ }^{1}$
}

\author{
Andreia Carvalho \\ Universidade de Coimbra
}

Resumo: "É talvez porque ali onde há voz, o sexo indecide-se" - eis a enigmática frase que Jacques Derrida nos deixa numa correspondência datada de 1982, intitulada “Voice II", a partir da qual se tentará salientar de que modo o pensamento derridiano da escrita como arqui-escrita e/ou différance, bem como a aproximação de um outro feminino pensado para além do binómio masculino-feminino, permitem repensar a dita "diferença sexual" (dual e oposicionalmente determinada) em termos de diferenças sexuais, nomeadamente a partir da dinâmica indecidível do que, ainda no mesmo texto, o filósofo refere como a "verdade da différance sexual".

Palavras-chave: Derrida, Desconstrução, diferenças sexuais, escrita, feminino

\begin{abstract}
Perhaps because where there is voice, sex becomes undecided" - this is the enigmatic sentence that Jacques Derrida leaves us in a correspondence dated of 1982, entitled "Voice II", from which I will try to highlight how Derrida's thought of writing as archi-writing and/or différance, as well as the approach of another feminine thought besides the binomial masculine-feminine, allow us to think differently the so-called "sexual difference" (dually and oppositionally determined) in terms of sexual differences, namely from the undecidable dynamic of what is referred, in the same text, as the "truth of sexual différance".
\end{abstract}

Keywords: Derrida; Deconstruction; feminine; sexual differences; writing 
Pourquoi parlons-nous tant de la voix alors que notre sujet, c'est la différence sexuelle?

C'est peut-être que là où il y a de la voix, le sexe s'indécide.

De ce "là" où il y a de la voix nous ne pourrons dire l'inouï - le très ancien ou le très nouveau - que si nous revenons [...] de ce que tous les savoirs, toutes les philosophies doivent présupposer de la voix. [...] Ils ne se contentent pas de la sous-entendre, ils en construisent la "grammaire" (non seulement celle qui distingue des voix, l'active, la passive ou la moyenne) pour assurer des identités locales des corps ou des âmes, des sujets, des "moi" - ou des sexes allant par deux.

Jacques Derrida

De entre as várias referências, mais ou menos explícitas consoante o seu contexto, que percorrem a obra derridiana relativamente à questão da "diferença sexual", irei privilegiar aqui uma frase deixada numa correspondência datada de 1982, intitulada "Voice II", a saber: "É talvez porque ali onde há voz, o sexo indecide-se" (Derrida 1992: 172). Desta frase, pedir-vos-ia que retivessem de momento apenas a sua primeira parte (talvez ali onde há voz) pois, constituindo um dos modos para aproximar o pensamento derridiano da escrita como arqui-escrita e/ou différance, esta enunciação permitirá aproximar aquilo que não somente excede mas que, ao mesmo tempo, transgride e resiste à possibilidade de "identificação" em geral, permitindo assim delinear um ponto de partida possível para repensar a dita "diferença sexual" em termos de diferenças sexuais ou, como referido ainda no mesmo texto, em termos de uma "sexualidade inumerável" (idem: 174).

A importância da questão da escrita para o pensamento da Desconstrução derridiana é, de facto, inegável, tanto por constituir, por um lado, um "sintoma particularmente revelador" (Derrida 1975: 15) do registo falogocêntrico da tradição filosófica grecoocidental como, por outro lado, pelo facto de a desconstrução da "concepção tradicional de escrita" permitir aproximar uma hiper-radicalidade e uma incondicionalidade inauditas no interior da ocidentalidade filosófica. Esta referência deixa assim implícito que se encontram aqui em questão diferentes concepções de escrita sem que estas sejam, contudo, opostas ou 
incompatíveis entre si, e sem que seja indiciada uma qualquer negação ou destruição da referida concepção tradicional, pois, como explicitado, nomeadamente, em Limited Inc., "o de- de desconstrução não significa a demolição do que se constrói, mas o anúncio do que resta a pensar diferentemente do esquema construtivista ou destrucionista” (Derrida 1990: 217).

Para tentarmos compreender o que seria isso que "resta a pensar" - implícito, justamente, no "talvez ali onde há voz" - começarei por enunciar, de modo necessariamente genérico, o que se entende por "falogocentrismo" e a sua relação à "concepção tradicional de escrita" referindo, primeiramente, que o termo logocentrismo, como a própria enunciação indica, marca a "autoridade" e o privilégio do logos pensado em termos de "centralidade" e de "poder de reunião" (havendo que ter em conta que logos reenvia aqui tanto a "verbo", "palavra" ou "discurso", como "pensamento" ou "razão", entre outros).

Definido como o "centro" de tudo o que seja pensável, incluindo o movimento em que se pensa e constitui a si mesmo, o logos surge assim como a possibilidade da verdade e do sentido em geral - movimento que se torna mais compreensível se tivermos em conta que o logocentrismo se constitui também como um fonocentrismo, ou seja, ao privilégio do logos corresponde o privilégio da sua suposta relação de imediatidade à voz, formando o que Derrida enuncia, nomeadamente em De la Grammatologie, como um "sistema do ouvirse falar" (Derrida 1967a: 17).

Além disso, este privilégio encontra-se sustentado numa configuração temporal baseada num privilégio da presença e na possibilidade da sua plenitude, sendo apenas a partir da suposta possibilidade de uma presença plena que se pode constituir e manter, como desenvolvido nomeadamente em "La Pharmacie de Platon", a oposição hierárquica entre "interioridade" e "exterioridade" que fundamenta a definição tradicional de escrita enquanto mera representação gráfica secundária, posterior e inferior. Marca-se também aqui o registo de degenerescência e de ilegitimidade da escrita relativamente à suposta anterioridade e superioridade da "palavra falada", como se perscruta, por exemplo, nesta passagem de De la Grammatologie:

Declaração de princípio, voto piedoso e violência histórica de uma palavra sonhando a sua plena presença a si, vivendo-se como a sua própria resumpção: dita linguagem, auto- 
produção da palavra dita viva, capaz, dizia Sócrates, de prestar assistência a si mesma, logos que crê ser de si mesmo o seu próprio pai, elevando-se assim acima do discurso escrito, infans e infirme de não poder responder quando se o interroga e que, tendo "sempre necessidade da assistência do seu próprio pai" [...] deve portanto ter nascido de um corte e de uma expatriação primeiras, votando-o à errância, ao enceguecimento e ao luto (idem: 56-57).

Neste sentido, o privilégio e a autoridade mantêm-se determinantemente do lado do dito "sujeito" que se ouve a si mesmo e que se afirma como "pai da palavra" (e é toda a linha da linguagem como "próprio do homem" que se perscruta aqui), afirmação que não está nunca longe de uma determinada "comparação" ao processo de geração e transmissão da vida que faz com que a "cena" se jogue apenas, como se pode ler em La Dissémination, "entre o pai e o filho: auto-inseminação, homo-inseminação, reinseminação" (Derrida 1972: 53).

O que gostaria de reter aqui é a "circularidade" inerente ao movimento pelo qual o dito "sujeito" se constitui a si mesmo a partir da possibilidade de um "discurso" interior, puro e silencioso que, posteriormente, se daria a ouvir no instante da "palavra falada" como representação imediata dessa mesma "interioridade" - movimento que subjaz ainda às noções de "indivíduo", de "intencionalidade", de "consciência", entre outras, e que não segue sem os contornos de um incontornável falocentrismo pois, ainda que nem sempre com a mesma evidência, ao movimento de auto-constituição do dito "sujeito" correspondeu determinantemente o privilégio do "masculino", mesmo diante de uma suposta neutralização que se quereria à margem da diferenciação sexual, como referido, nomeadamente, em "Women in the beehive":

0 que se poderia chamar a neuterização das marcas sexuais tem, como se sabe, o efeito de dar poder aos homens. Quando se diz, "Bem, estamos em campo neutro, não há diferença”, todos sabemos que neste caso o sujeito será um homem. Portanto, isto é um engodo clássico do homem para neutralizar a marca sexual. [...] Portanto, tendo em conta que a universalidade implica neutralização, podemos estar certos de que é somente um modo escondido de confirmar o homem no seu poder. (Derrida 2005: 146$)^{2}$

N. 39 - 12/ 2018 | 53-70 - ISSN 2183-2242 | http:/dx.doi.org/10.21747/21832242/litcomp39a4 
A questão da secundarização da escrita surge assim, num primeiro momento, como um modo para identificar os fundamentos do registo falogocêntrico, ${ }^{3}$ contudo, se a escrita foi sempre pensada como "ausência" inferior à "presença", "exterioridade" inferior à "interioridade", "silêncio" inferior à "palavra falada", coloco agora uma primeira questão: o que acontece se tentarmos pensar uma ausência absoluta que não seja mais o oposto da "presença"? Como se poderá pensar um certo silêncio que não seja mais a ausência da "voz", mas o seu limite como sua condição? E como se poderá pensar uma voz que não se deixe mais consignar, nas palavras de Derrida, a uma das marcas do "mesmo e pobre código binário" (Derrida 1992: 173)? Ou, em última instância, para além das dicotomias hierárquicas, o que seria isso que "resta a pensar"?

Uma hipótese de resposta a estas questões passa por aproximar um outro "sentido" de escrita que, nomeadamente em De la Grammatologie, surge sob o quase-conceito de arqui-escrita,4 e que, não se definindo mais pela determinação circular do "ser como presença" (Derrida 1967b: 103), marca, diferentemente, uma incondicionalidade absoluta e irredutível, nomeadamente ao dar a pensar a escrita, seguindo as palavras de Résistances de la psychanalyse, como constituindo "no coração do presente, na origem da presença, um movimento de reenvio ao outro" (Derrida 1996a: 42).

Neste contexto, o termo "escrita" não reenvia portanto apenas ao seu sentido corrente de representação gráfica secundária; contudo, para tentar compreender este deslocamento haveria que ter em conta o que, nomeadamente em Posições, é avançado como uma espécie de "estratégia geral da desconstrução" (Derrida 1975: 53), indispensável também para aproximar o movimento indecidível de uma "différance sexual" pensada para além da diferença dicotómico-hierárquica masculino-feminino.

Este gesto, ainda que muito mais complexo do que esta breve descrição, passaria por, a partir do reconhecimento de um determinado par oposicional (por exemplo, palavra falada/palavra escrita), tentar repensar o termo tendencialmente secundarizado (neste caso, a escrita como representação gráfica secundária) e, a partir desse repensar, aproximar 
o que excede, transgride e resta in-finitamente a essa mesma oposição, bem como ao esquema dicotómico-hierárquico em geral, sem lhe permanecer simplesmente exterior (e que seria a escrita no sentido de arqui-escrita ou différance).

Esta seria uma das vias para compreender o que Derrida refere, por exemplo, em "La Mélancolie d'Abraham", como um gesto de paleonímia que consiste em conservar uma velha palavra ali onde a significação desta "despertou para outra coisa" (Derrida 2012: 33), sendo também neste sentido que os quase-conceitos de escrita e de différance, entre outros que formam os incondicionais ou os "impossíveis" (Derrida 1996a: 44) da Desconstrução derridiana, podem ser entendidos como "marcas textuais" que desestabilizam o esquema da conceptualização tradicional ao marcarem, no interior desse esquema, algo que permanece, a priori, absolutamente inapropriável.

Por conseguinte, ao marcar um "movimento de reenvio ao outro", o termo escrita marca precisamente isso que "resta a pensar" e que não pode aproximar-se senão a partir de uma temporalidade excessiva e anacrónica (messiânico) que escapa a qualquer tentativa de presentificação plena. Todavia, este excesso não constitui uma abstracção que permaneceria à margem do "real", mas é antes "nisso" (na “origem", na "verdade", na "presença", no "sentido", ou mesmo no dito "sujeito"), a excepção a "isso", transgredindo-o in-finitamente enquanto limite de toda a plenitude identitária no mesmo lance em que enceta um processo de (des)identificação sem fim.

Eis o que se encontra implícito no "talvez ali onde", a saber: a dinâmica in-finita de um tempo excessivo e inapropriável que, a cada instante, rasga o presente dito vivo e abre ao talvez, ao tempo aporético de um "talvez" que, não podendo jamais constituir-se como presença plena, não é nem uma utopia, nem uma abstracção, mas antes a chance do "aqui agora" onde o outro pode, talvez, chegar ou acontecer, como o filósofo refere, nomeadamente, em Políticas da Amizade, assumindo que “[t]alvez o impossível seja a única chance possível de qualquer novidade, de qualquer nova filosofia da novidade. Talvez, talvez na verdade o talvez nomeie ainda esta chance [...]" (Derrida 2003: 49).

Relativamente ao esquema da "subjectividade" que referi, a escrita apontaria assim para o que não se deixa delimitar pelo movimento de "auto-inseminação" nem pela 
circularidade idealizante da "palavra falada", engendrada e preservada pelo "pai", apontando antes para a dinâmica inapropriável de uma disseminação originária que afirma a geração já sempre dividida do sentido e que prefigura, como referido em Posições, "o que não volta ao pai" (Derrida 1975: 95) - e que corresponderia, em última instância, a isso que "me precede e se apodera de mim aqui agora [...]. Como o outro. Como a différance irredutível e não reapropriável do outro" (Derrida 2009: 164-165).

Ora, é neste contexto que se torna possível perscrutar a hiper-radicalidade e a incondicionalidade do pensamento derridiano da escrita como arqui-escrita e/ou différance, na medida em que, para Derrida, o outro é absolutamente todo e qualquer outro - "tout autre est tout autre" (Derrida 2003: 104), na singular intraduzibilidade da sua escrita ${ }^{5}$-, havendo assim que ter em conta que o outro, como pode ler-se em De Quoi Demain,

[...] não é necessariamente um outro homem, o meu semelhante, o meu irmão, o meu próximo. Isso pode ser também uma "vida" ou mesmo um "espectro", e não somente definível segundo as seguranças binárias da homo- ou da heterossexualidade. Eis o que pode ser, o que deve ser um evento digno desse nome, uma chegança [arrivance] que me surpreende absolutamente e à qual ou a quem, da qual ou de quem não posso, não devo mais não responder - de maneira tão responsável quanto possível. (Derrida 2001a: 90-91)

Nesta passagem escutamos, ao mesmo tempo, a primazia e a anterioridade da vinda do outro como evento, bem como a abertura incondicional do "eu" diante do outro pensada em termos de um acolhimento, de uma resposta e de uma responsabilidade que antecedem e excedem qualquer marca identificatória, seja esta formal, figural, topológica, genealógica, sexual ou outra, encontrando-se também aqui uma das vias a partir das quais Derrida pensa diferentemente a questão do feminino, nomeadamente tal como esta é exposta na sua singular leitura do feminino no pensamento de Emmanuel Lévinas.

Embora de modo necessariamente sumário, notemos que, à primeira vista, a terminologia levinasiana parece de facto bloquear qualquer interpretação que não a que lhe evidencie um clássico androcentrismo, encontrando-se a "alteridade feminina", nomeadamente em Totalidade e Infinito, directamente ligada à "habitação" e à "intimidade 
da casa", e sendo mesmo descrita como uma linguagem silenciosa e "sem ensino" (Lévinas 2008: 147-148). Contudo, esta descrição oferece-se em si mesma a mais de uma leitura, por um lado, pelo facto de a própria terminologia levinasiana não se prender mais a uma significação tradicional, e, por outro lado, pelo facto de um certo "feminino" ser também aproximado, como salienta Derrida, como o "acolhimento por excelência" (Derrida 1997: 45) - sendo, neste sentido, prévio à universalidade da linguagem, incluindo, todavia, em si todas as possibilidades da relação a outrem.

Ora, é precisamente esta pelo menos dupla leitura que Derrida expõe, nomeadamente, em Adieu - à Emmanuel Lévinas, assumindo mesmo poder perscrutar-se aí, na aproximação levinasiana do feminino como acolhimento, uma "espécie de manifesto feminista" (idem: 83) que apontaria para uma "radicalidade essencial e meta-empírica que tem em conta a diferença sexual numa ética emancipada da ontologia" (idem: 83) e que, nesse sentido, se demarca dos riscos de uma essencialização ou de uma idealização da "mulher" ou do "feminino", sem todavia depender nem implicar uma determinação sexual de cariz anatómico ou biológico.

Nesta orientação, e tendo em conta a singularidade que caracteriza cada um destes motivos em sede desconstrutiva, pode assumir-se que um outro feminino é aproximado a partir de um gesto semelhante ao gesto pelo qual é aproximada a escrita (como arquiescrita), e a indecidibilidade que caracteriza o feminino - uma indecidibilidade que, é preciso bem notar, permanece indissociável do seu registo imediata e incondicionalmente afirmativo $^{6}$ - a indecidibilidade que caracteriza o feminino, dizíamos, aponta, portanto, para isso que não somente antecede $e$ excede a determinação dual e oposicional da dita "diferença sexual", mas que, ao mesmo tempo, divide $e$ pluraliza cada um dos termos que a constituem. ${ }^{7}$

Esta indecidibilidade encontra-se também implícita, por exemplo, em Éperons. Les Styles de Nietzsche, onde um certo "feminino" aparece como aquilo que resiste à formulação falogocêntrica do conceito de "verdade",8 ou ainda em La Dissémination, nomeadamente na aproximação do quase-conceito de "hímen" que designaria o movimento de uma diferença (a différance) que desloca a determinação oposicional sem, contudo, suprimir os diferentes e 
as diferenças, mas dando antes a pensar o que (se) passa entre dois termos ao mesmo tempo que disjunta um e outro sem, contudo, ser nem um nem outro. ${ }^{9}$ Um entre que não seria, portanto, nem feminino nem masculino e que, sem constituir qualquer neutralização, evidenciaria antes que "o que resta indecidível", seguindo as palavras de "Chorégraphies", "não concerne somente mas também o traço de clivagem entre os dois sexos" (Derrida 1992: 112).

É justamente a indecidibilidade que im-possibilita este "traço de clivagem" que gostaria de dar a escutar, salientando agora que a referência ao "talvez ali onde há voz" marca também a indissociabilidade entre a questão da língua e a questão do tempo, bem como a incondicionalidade que caracteriza a aproximação de ambas as questões em sede desconstrutiva, como se perscruta desde De la Grammatologie, nomeadamente quando Derrida assume que a "estrutura geral do rastro imotivado faz comunicar na mesma possibilidade, e sem que se possa separá-los senão por abstracção, a estrutura da relação ao outro, o movimento da temporalização e a linguagem como escrita" (Derrida 1967a: 67).

Neste sentido, a temporalidade (messiânica) que referi é também a que subjaz a um outro pensamento da língua e que desconstrói a suposta "unidentidade" desta, implicando pensá-la em termos de uma "unicidade sem unidade" (Derrida 2001: 101) ou, como avançado em Mémoires pour Paul de Man, em termos de "plus d'une langue" (Derrida 1988: 38) - expressão que, permitindo a dupla escuta de "mais de uma língua" $e$ "nem (mais) uma língua", surge aí como uma das quase-definições da Desconstrução. ${ }^{10}$

Esta questão é aqui indispensável na medida em que a relação à língua constitui um ponto incontornável para pensar o processo de "identificação subjectiva" do "eu”, devendo ter-se em conta pelo menos dois aspectos, a saber: por um lado, que a língua não se define mais nem como uma construção derivada do "sujeito" nem como uma "propriedade" que este possa possuir - pois o tempo da vinda do outro inscreve-se na língua como um desvio inapropriável que a desvia tanto do "referente" e do "sentido" como de si mesma, impossibilitando assim a oposição entre "palavra falada" e "palavra escrita" e evidenciando 
que as características que tradicionalmente contribuíram para a secundarização da escrita constituem, antes, o movimento da linguagem em geral.

E, por outro lado, que este desvio da língua e na língua - um dos modos, justamente, para pensar o "traço de clivagem" - desvia também o "eu" de "si mesmo", na medida em que a chance da sua (des)identificação ocorre no interior de uma experiencia de ex-apropriação originária da língua que torna antecipadamente o processo de "identificação subjectiva" do "eu" numa "experiência finita de não-identidade a si" (Derrida, 1992: 280).

Neste sentido, esta experiência de ex-apropriação não diz mais, portanto, o "próprio do homem", mas traduz e testemunha a dissimetria e a desproporção de um "duplo movimento pelo qual", como pode ler-se em Échographies - de la télevision, "me inclino para o sentido tentando apropriá-lo, mas ao mesmo tempo sabendo e desejando que ele me permaneça estrangeiro, transcendente, outro" (Derrida 1996b: 123-124) - sendo precisamente esta dissimetria que constitui, como referido em "Chorégraphies", "a lei da diferença sexual e da relação ao outro em geral” (Derrida 1992: 114).

Mas como escutar então, no seguimento desta experiência finita de não-identidade a si, a referência à "voz"?

De facto, a voz não é mais compreendida em termos de "propriação", nem como uma simples "parte" ou "pertença" do "corpo", mas, enquanto rastro, isto é, entendida a partir da dinâmica inapropriável da "escrita na voz" (idem: 150); é a sua própria constituição que passa pela possibilidade sempre possível de um certo desligamento ou de um certo despreendimento:

[u]ma voz pode desprender-se de um corpo, [pode] cessar, desde o primeiro instante, de lhe pertencer. Pelo que traça, é rastro, espaçamento, escrita: nem simples presença, nem significância. É do corpo, mas porque a este corpo, ela o atravessa, dispõe dele, não lhe guarda quase nada, de passagem dá-lhe talvez lugar mas não tem nele, por exemplo nele enquanto é sexualmente determinado, o seu lugar. Uma voz pode dar nascença, eis, a um outro corpo. (idem: 172)

Encontramo-nos assim perante um outro "ponto de partida" sem começo presentemente identificável e que abre ao infinito as hipóteses de leitura - uma certa 
"interioridade telefónica", como é dito em Ulysse Gramophone, viria "inscrever a distância, a différance e o espaçamento na phone" (Derrida 1987: 82) dando assim a pensar a voz, cada voz, como "mais de uma" e "nem mais uma" [plus d'une voix] (Derrida 2004: 24).

Por outras palavras, ao deslocar o "ponto de partida", isto é, ao demonstrar a impossibilidade de uma voz dita "una", desloca-se também, necessariamente, aquilo que determinantemente uniu o movimento circular de "auto-constituição" à determinação aparentemente segura de um "sexo", gesto que implica pensar não um "corpo" detentor de uma "voz" (por exemplo, um corpo do sexo masculino detentor de uma voz dita masculina, bem como um corpo do sexo feminino detentor de uma voz dita feminina), mas antes a(s) voz(es) que transgride(m) o "corpo" e que, não lhe pertencendo, o marcam para além de toda a dualidade e de toda a neutralidade supostas ou desejadas.

Mas é justamente por isso, por permanecer, de uma certa maneira, sem lugar assinalável e por, consequentemente, se desprender do corpo dito próprio, que a voz nos obriga a pensar "uma diferença vocal rebelde à oposição e que não pode permanecer à disposição, órgão e poder significante, de uma pessoa ou de um eu, de uma consciência ou de um inconsciente, nem de um dos dois sexos. A própria bissexualidade não lhe basta" (Derrida 1992: 173).

Neste sentido, ao ser pensada como uma singular "força de afirmação rebelde" (idem: 174) que, sendo do "corpo", o ultrapassa, a voz vem deslocar as oposições e desmontar as hierarquias, complicando os limites entre "interioridade" e "exterioridade" e evidenciando o carácter sempre inacabado, precário ou, muitas das vezes, fictício mesmo, de uma "identidade" que não é nunca efectiva ou alcançada, existindo somente, como pode ler-se em "Ja, ou le faux-bond", "um processo, o efeito de um processo de ex-apropriação que não "produz" senão perspectivas, leituras sem verdade, diferenças, cruzamentos de afecto, toda uma "história" onde a própria possibilidade está a desinscrever ou [a] reinscrever" (idem: 58).

A estas perspectivas, a estas diferenças ou a estes cruzamentos, Derrida chama, também, "idioma", e seria precisamente a partir de uma certa "voz idiomática" que antes, ou talvez para além da formulação dicotómica da dita "diferença sexual", haveria que pensar 
uma "relação diferentemente sexuada" (idem: 114) que, sem centro de organização fixo, abriria o "idioma de uma diferença sexual inimitável” (idem: 175).

Consequentemente, percebemos que um pensamento do idioma singular não se enquadra nem se delimita em definições biológicas ou anatómicas, o que em momento algum visa invalidá-las ou ignorá-las, mas sim evidenciar que permanece sempre algo que não é apropriável pelos registos do "ver" e do "saber" em geral, motivo pelo qual Derrida assume ser preciso “Mais e menos anatomia!” (idem: 178).

De igual modo, este pensamento incita uma espécie de estado de alerta ou de "vigília" constante relativamente a determinadas interpretações que persistem por vezes presas aos traços dos quais desejam separar-se, nomeadamente ao assumirem a possibilidade efectiva de responder às questões "o que é o feminino?", ou "o que é a mulher?", sustentando-se, em última instância, numa definição de "identidade" ainda pensada em termos de propriação e de propriedade "segundo um modo conhecido do conceito ou do saber" (Derrida 1978: 57). ${ }^{11}$

Não se tratando nunca de um confronto nem de uma secundarização de consequências ditas práticas, o que estaria aqui em questão seria uma espécie de problematização de "princípios" que desloca a própria distinção entre "teoria" e "prática", e a partir da qual haveria que tentar pensar diferentemente a dita "diferença sexual" a partir de uma "escrita da voz singular" (Derrida 1992: 175) entendida como resistência in-finita a toda a normatividade, tanto aos estereótipos em particular como ao "tipo" em geral, embora apelando por isso mesmo, como resistência, a um gesto de leitura e de interpretação infinito.

Uma “inumerável sexualidade em séries abertas" (idem: 174) - eis, talvez, o que "resta a pensar", e que se marca não apenas na diferença entre os termos, mas no desvio ou na différance que impossibilita antecipadamente a identificação plena de qualquer termo, ou seja, não apenas na diferença entre "feminino" e "masculino" mas também, e talvez antes mesmo, na diferença entre um certo "feminino" e ele mesmo, na diferença entre um certo "masculino" e ele mesmo - em suma, na diferença entre qualquer "si mesmo" que é já 
sempre, antecipadamente, mais de um e nem mais um [plus d'un], sendo neste sentido que se deve tentar compreender o momento em que, em "Voice II", Derrida assume:

Eis o que se anuncia quando escrevo por exemplo isto, mesmo se é falso. Pura e simplesmente quando o escrevo e que se produz então este êxtase que consiste em pensar, para o amar, o impossível. Mesmo se é falso, o que escrevo, e mesmo que o escreva, que o cante segundo tal voz, que eu pense desejar o que não posso conhecer, o impossível, eis o que vem testemunhar aqui mesmo, se quiserem, que através do falso é preciso que se anuncie o que se inscreve em falso contra o "verdadeiro". É para mim, agora, a verdade da différance sexual. (Derrida 1992: 175)

Trata-se assim de tentar pensar que não há verdade da "diferença sexual" precisamente por não haver "a" diferença sexual mas sim o idioma de diferenças sexuais singulares e inimitáveis que não podem ser apropriadas, definidas ou agrupadas sem resto, mas que se oferecem por aí mesmo, por este transbordamento e por este deslocamento "da" verdade, a uma leitura e a uma interpretação na qual o "falso" não tem lugar, não mais do que o "verdadeiro" de acordo com a sua determinação tradicional.

Em jeito de conclusão necessariamente inacabada, uma certa "sexualidade" não pode, pois, senão "indecidir-se", e, mais do que "a" diferença sexual, seria preciso pensar as diferenças sexuais que atravessam e dividem cada "corpo" - pois a "verdade da différance sexual", se a houver, apontaria justamente para a resistência absoluta e absolutamente singular que passa não apenas entre os dois, ou mais, sexos, mas entre cada sexo e "ele mesmo", não se oferecendo nunca a uma delimitação totalizada, mas permanecendo entre as diferenças e entre cada diferença, permanecendo entre os diferentes e entre cada diferente, e, nesse sentido, permanecendo sempre, como Derrida afirma, nomeadamente em "Formiga's",

[...] para interpretar, para decifrar, para desencriptar, para ler e não para ver. Legível, logo invisível, objecto de testemunho e não de prova - e, no mesmo lance, problemática, móvel, não segura, ela passa, ela está de passagem, ela passa de um ao outro, por um e pelo outro, de uma à outra como uma formiga, um formiga de sonho. (Derrida 1994: 55) 


\section{NOTAS}

${ }^{1}$ Este texto foi primeiramente apresentado no Congresso Internacional Intersexualidades: Cruzando Corpos, Cruzando Fronteiras, que decorreu na Faculdade de Letras da Universidade do Porto e na Fundação de Serralves, de 23 a 25 de Março de 2017.

2 Excepto quando indicado, todas as traduções são nossas.

${ }^{3}$ Como salientado por Élisabeth Roudinesco, nomeadamente em De quoi demain, o "falogocentrismo" reportase ao “[...] primat accordé d'une part par la philosophie occidentale au logos platonicien, et, de l'autre, par la psychanalyse à la symbolique gréco-freudienne du Phallus selon laquelle il n'existerait qu'une seule libido (ou énergie sexuelle) et que celle-ci serait d'essence masculine" (Roudinesco 2003: 46).

4 "Archi-écriture dont nous voulons ici indiquer la nécessité et dessiner le nouveau concept; et que nous ne continuons à appeler écriture que parce qu'elle communique essentiellement avec le concept vulgaire de l'écriture" (Derrida 1967a: 75).

5 Para uma aproximação da incondicionalidade do pensamento da Desconstrução derridiana a partir do sintagma "tout autre est tout autre", veja-se, nomeadamente, o texto de Fernanda Bernardo: "Do 'Tout autre' (Lévinas/Derrida) ao 'Tout autre est tout autre' (Derrida): Pontos de não-contacto entre 'Lévinas $e$ Derrida', Revista Ítaca, n. $14,2009,238-266$.

60 registo imediata e incondicionalmente afirmativo inerente à indecidibilidade que caracteriza o feminino pensado em sede desconstrutiva é exposto, por exemplo, em Parages, obra onde, em torno de Maurice Blanchot, Derrida escreve:

Tout le transfert du code (par exemple “je l'ai aimée et n'ai aimé qu'elle”) fait latéralement, comme par un accompagnement silencieux de la langue, peser, pencher la "pensée", ou ailleurs la "parole" du côté féminin; c'est littéralement un movimentum, un moment féminin; il annonce par pression inconsciente la différence sexuelle avant tout autre détermination, tout autre identification. Et comme elle ne se détermine, ne s'appelle qu'à partir du viens qu'elle lance et renvoie, l'éloignement du viens instruit le pas de différence sexuelle. (Derrida 1986: 81)

7 Reenviamos aqui ao texto de Fernanda Bernardo, intitulado "Femininidade e Hospitalidade em Lévinas. A difícil incondição do "humano" hóspede/refém de outrem", onde pode ler-se,

Um 'feminino' que assim pensado - assim, quer dizer: antes, para além e diferentemente da própria 'diferença sexual', insistimos -, abre e heterogeneíza esta 'diferença' (Derrida falará por isso de 'diferenças'), abrindo, pluralizando e heterogeneizando cada 'um' dos seus termos que, em si mesmos, são, por isso, já sempre 'mais de um'. Ou então, 'nem mais um', uno e/ou idêntico (Plus d'un, dirá de uma assentada Derrida). 0 que pressupõe que 
uma tal 'femininidade' não só desenha a dissimetria - e portanto a ininterrupta interrupção - da relação quase dual entre os dois sexos, como a de cada um deles consigo mesmo... (Bernardo 2011: 25-26)

${ }^{8}$ Neste contexto, Derrida afirma, em Éperons:

Ce qui à la vérité ne se laisse pas prendre est - féminin, ce qu'il ne faut pas s'empresser de traduire par la féminité, la feminité de la femme, la sexualité féminine et d'autres fétiches essentialisants qui sont justement ce qu'on croit prendre quand on reste à la niaiserie du philosophe dogmatique, de l'artiste impuissant ou du séducteur sans expérience. (Derrida 1976: 43)

9 “Grâce à la confusion et à la continuité de l'hymen, non pas en dépit de lui, s'inscrit une différence (pure et impure) sans pôles décidables, sans termes indépendantes et irréversibles. Telle différance sans présence apparaît ou plutôt déjoue l'apparaître en disloquant un temps ordonné au centre du présent" (Derrida 1972: 238).

10 “Si j'avais à risquer, Dieu m’en garde, une seule définition de la déconstruction, brève, elliptique, économique comme un mot d'ordre, je dirais sans phrase : plus d'une langue" (Derrida 1988: 38).

11 O repensar da dita "diferença sexual" em termos de diferenças sexuais excede, por conseguinte, tanto a dita "diferença sexual" dual e determinantemente organizada por caracteres biológicos, como a sua suposta neutralidade por vias de um apagamento ou de uma suspensão da diferenciação sexual, excedendo no mesmo lance a noção de um gender socio-performativo - sendo esta última distinção desenvolvida, por exemplo, por Peggy Kamuf em "Derrida and gender: the other sexual difference" [in Tom Cohen (ed.), Jacques Derrida and the Humanities. A Critical Reader, State University of New York, Albany, 2002, principalmente pp. 82-87], bem como por Anne-Emmanuelle Berger em "Sexing Differences" [in differences: A Journal of Feminist Cultural Studies, 16.3, 2005, Brown University, principalmente pp. 58-59]. 


\section{Bibliografia}

Berger, Anne-Emmanuelle, (2005) "Sexing Differances", differences: A Journal of Feminist Cultural Studies, vol. 16, n. 3, Brown University, 52-67.

Bernardo, Fernanda, (2008), "Do 'Tout autre' (Lévinas/Derrida) ao 'Tout autre est tout autre' (Derrida): Pontos de não-contacto entre 'Lévinas e Derrida'”, Revista Ítaca, n.․ 14, 238-266.

-- (2011), “Femininidade e Hospitalidade em Lévinas. A difícil incondição do 'humano' hóspede/refém de outrem", in M. Lucília Marcos / M. João Cantinho / P. Barcelos (orgs.), Emmanuel Levinas - entre Reconhecimento e Hospitalidade, Lisboa, Edições 70, 149-207.

Derrida, Jacques (1967a), De la Grammatologie, Paris, Minuit.

-- (1967b), "A estrutura, o signo e o jogo no discurso das ciências humanas", Trad. A. Ramos Rosa, in E. Prado Coelho (sel.), Estruturalismo. Antologia de textos teóricos, Lisboa, Portugália Editora, 101-123 [1962].

-- (1972), La Dissémination, Paris, Seuil.

-- (1975), Posições, Trad. Maria M. C. Calvente Barahona, Lisboa, Plátano Editora [Positions, Paris, Minuit, 1972].

-- (1978), Éperons. Les styles de Nietzsche, Paris, Flammarion.

-- (1986), Parages, Paris, Galilée.

-- (1987), Ulysse Gramophone, Paris, Galilée.

-- (1988), Mémoires pour Paul de Man, Paris, Galilée.

-- (1990), Limited Inc., Paris, Galilée.

-- (1992), Points de Suspension, Paris, Galilée.

-- (1996a), Résistances - de la psychanalyse, Paris, Galilée. 
-- (1996b), Échographies - de la télévision, Paris, Galilée.

-- (1997), Adieu - à Emmanuel Lévinas, Paris, Galilée.

-- (2001), O Monolinguismo do outro, Trad. Fernanda Bernardo, Porto, Campo das Letras [Le Monolinguisme de l'Autre, Paris, Galilée, 1996].

-- (2003), Políticas da Amizade, Trad. Fernanda Bernardo, Porto, Campo das Letras [Politiques de l'amitié, Paris, Galilée, 1994].

-- (2005), "Women in the beehive: A seminar with Jacques Derrida", differences: A Journal of Feminist Cultural Studies, vol. 16, n. , Brown University, EUA, 139-157 [1984].

-- (2009), Vadios, Trad. Fernanda Bernardo et. al., Coimbra, Palimage [Voyous, Galilée, Paris, 2003].

-- (2012), “La Mélancholie d'Abraham”, Les Temps Modernes, n. 669-570, 31-66 [2004].

-- (2018), "Formiga's", Trad. Fernanda Bernardo, in Jacques Derrida/Hélène Cixous, Idiomas da diferença sexual, Coimbra, Palimage, 49-83 ["Fourmis" in Mara Negron (ed.), Lectures de la Différence Sexuelle, Paris, Des Femmes, 1994, 69-102].

Derrida, Jacques/ Roudinesco, Elisabeth (2003), De quoi demain, Paris, Flammarion [2001].

Derrida, Jacques/ Cixous, Hélène (2004), "Du mot à la vie: un dialogue entre Jacques Derrida et Hélène Cixous", Le Nouveau Magazine Littéraire, n. ${ }^{\circ}$ 430, 22-29.

Kamuf, Peggy (2002), "Derrida and gender: the other sexual difference”, in Tom Cohen (ed.), Jacques Derrida and the Humanities. A Critical Reader, State University of New York, Albany, 82-107.

Lévinas, Emmanuel, (2008) Totalidade e Infinito, Trad. José Pinto Ribeiro, Lisboa, Edições 70 [Totalité et Infini, La Haye, Martinus Nijhoff, 1961]. 
Andreia Carvalho concluiu tanto a sua Licenciatura em Filosofia (2010) como o seu Mestrado em Filosofia (2012) na Faculdade de Letras da Universidade de Coimbra, onde presentemente aguarda prova de defesa pública da sua tese de Doutoramento (sob o título “Aporias de uma 'escrita no feminino': Derrida-Cixous") em torno do pensamento da Desconstrução de Jacques Derrida e da escrita poético-pensante de Hélène Cixous. Foi bolseira da Fundação para a Ciência e a Tecnologia, é co-tradutora de livros e de textos no âmbito da Desconstrução, e co-organizou, entre outros, o "Colloque International de PostGraduation en Déconstruction. Héritages et Promesses de la Déconstruction" (2014). Tem como principais interesses de investigação: Desconstrução, Estudos de Género, Literatura. 